\title{
GENETIC INCOMPATIBILITY BETWEEN POPULATIONS OF THE NYMPHALID BUTTERFLY BOLORIA SELENE FROM ENGLAND AND THE UNITED STATES
}

\author{
CHARLES G. OLIVER* \\ Department of Biology \\ West Virginia University, Morgantown, West Virginia, U.S.A.
}

Received 2.i.77

\begin{abstract}
SUMmary
Laboratory hybrids were made between populations of the nymphalid butterfly Boloria selene from England and Massachusetts, U.S.A. The populations differ in phenotypic appearance, voltinism, and larval survival on two Viola species. The hybrids showed relatively high genetic incompatibility between the parental populations. This was manifested by lowered embryonic viability, a deficiency of female hybrid adults, and dwarfing of adults. The degree of incompatibility between the populations indicates a relatively large amount of genetic differentiation, which may be as great as that between separate, closely-related species.
\end{abstract}

\section{INTRODUCTION}

Comparatively few animal species have natural ranges so extensive as to include most of the North Temperate Zone of both the Old and New Worlds. Many such widely-ranging species are migratory or otherwise highly vagile, but some are small in individual size, sedentary, and highly habitatrestricted. As I have discussed in an earlier paper (Oliver, 1972a), species of the latter type can be expected to conform to the "stepping stone" model of population structure (Kimura and Weiss, 1964) and to show genetic differentiation between populations that is geographically (i.e. distance) correlated. This paper attempts to evaluate the degree of genetic compatibility between English and eastern North American populations of an apparently sedentary, habitat-restricted insect species, the nymphalid butterfly Boloria selene (Schiffermüller).

$B$. selene has a continuous range from Great Britain through Europe and Asia to Alaska and south and east to the northern United States. In general, adult geographic variation in this species is in the form of clines in ground colour and in the extent of the dark wing-pattern components. If geographic genetic differentiation within the species is in the form of clines similar to those expressed phenotypically, then one would expect the greatest genetic differentation within the species to be between populations from the eastern and western extremes of the range. In fact, because of the apparent population structure of the species and the tremendous distance between the extremes of its range, genetic differentiation between populations from the eastern United States and England may approach the maximum found in nature within clinal species.

During the summer of 1971 I was able to bring cultures of English $B$. selene to the United States and to cross them with stock from Massachusetts. Because of the difficulties encountered in obtaining English $B$. selene, trans-

*Present address: R.D.1, Box 78, Scottdale, Pa. 15683, U.S.A. 
porting live cultures over international boundaries, and achieving synchrony of adult emergence in the two population cultures, it is unlikely that I will make more hybrids involving Old World populations of B. selene in the near future. Therefore, I am presenting my data now even though they are not as complete as I might wish.

\section{Methods}

Wild-fecundated females were collected from populations in Pamber Forest, Silchester, Berkshire, England, and Axton, Middlesex Co., Massachusetts, U.S.A. Cultures were begun by confining the females over leaves of Viola papilionacea (in the U.S.A.) or V. canina (in England). Larvae were reared on cut Viola leaves in 3-inch plastic cups covered with netting. Hybrid broods were produced by crossing cultured $F_{1}$ females with cultured $\mathrm{F}_{1}$ or wild-collected males. At the same time pure outbred English stock was maintained so that hybrid backcrosses could be made without inbreeding the stock. All matings were accomplished by the hand-pairing technique (Clarke, 1952).

The natural habitats of the wild populations were compared casually in the field during collection of breeding stock. Observations were made on parental and hybrid phenotypic appearance and on the egg fertility, embryonic viability, sex ratio, mortality, and voltinism of laboratory broods of the parental population cultures and hybrids between them. Control broods of the parental population stocks and the hybrid broods were reared concurrently under the same environmental conditions (photoperoid approximately $18 \mathrm{hl} / 24 \mathrm{~h}$; temperature $18-25^{\circ} \mathrm{C}$ ). Data on egg fertility, embryonic viability, sex ratio, and voltinism were treated statistically by Wilcoxon's Criterion T.

\section{Comparison of populations}

Both populations occur in marshy meadows. The only Viola found at the Pamber Forest locality was $V$. canina, which is presumably the larval foodplant. The plants were growing just within the forest edge, and adult $B$. selene were seen only in the meadow and at the edge of the forest. Viola blanda was the dominant Viola species and probably a foodplant at the Massachusetts locality. In 15 years of observation of $B$. selene in the United States and Canada no individuals were ever found even a few yards away from marshy or boggy meadow habitats. My observations indicate that the species is local and little inclined to wander from its restricted habitat. Newly-hatched Massachusetts larvae taken to England grew and survived poorly on $V$. canina; newly-hatched English larvae brought to the United States did not survive as well as did the Massachusetts larvae on $V$. papilionacea, an eastern North American violet (table 2).

The Massachusetts population is multivoltine in nature with two broods (June and September). In the laboratory, cultures will breed continuously with no incidence of diapause (six broods observed over 3 years). In the laboratory an average of 31.6 per cent of the English larvae that survived the first instar (photoperiod approximately $18 \mathrm{hl} / 24 \mathrm{~h}$; temperature $18-25^{\circ} \mathrm{C}$ ) entered diapause later on (table 2), cven though the population appears to be univoltine in nature with the flight occurring in June. No adults were 

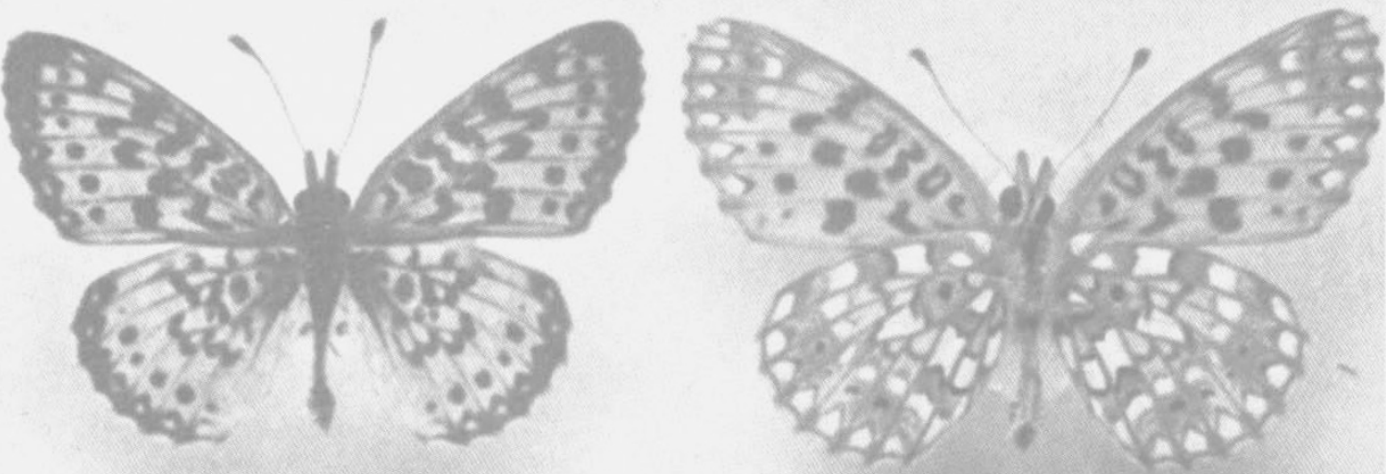

B
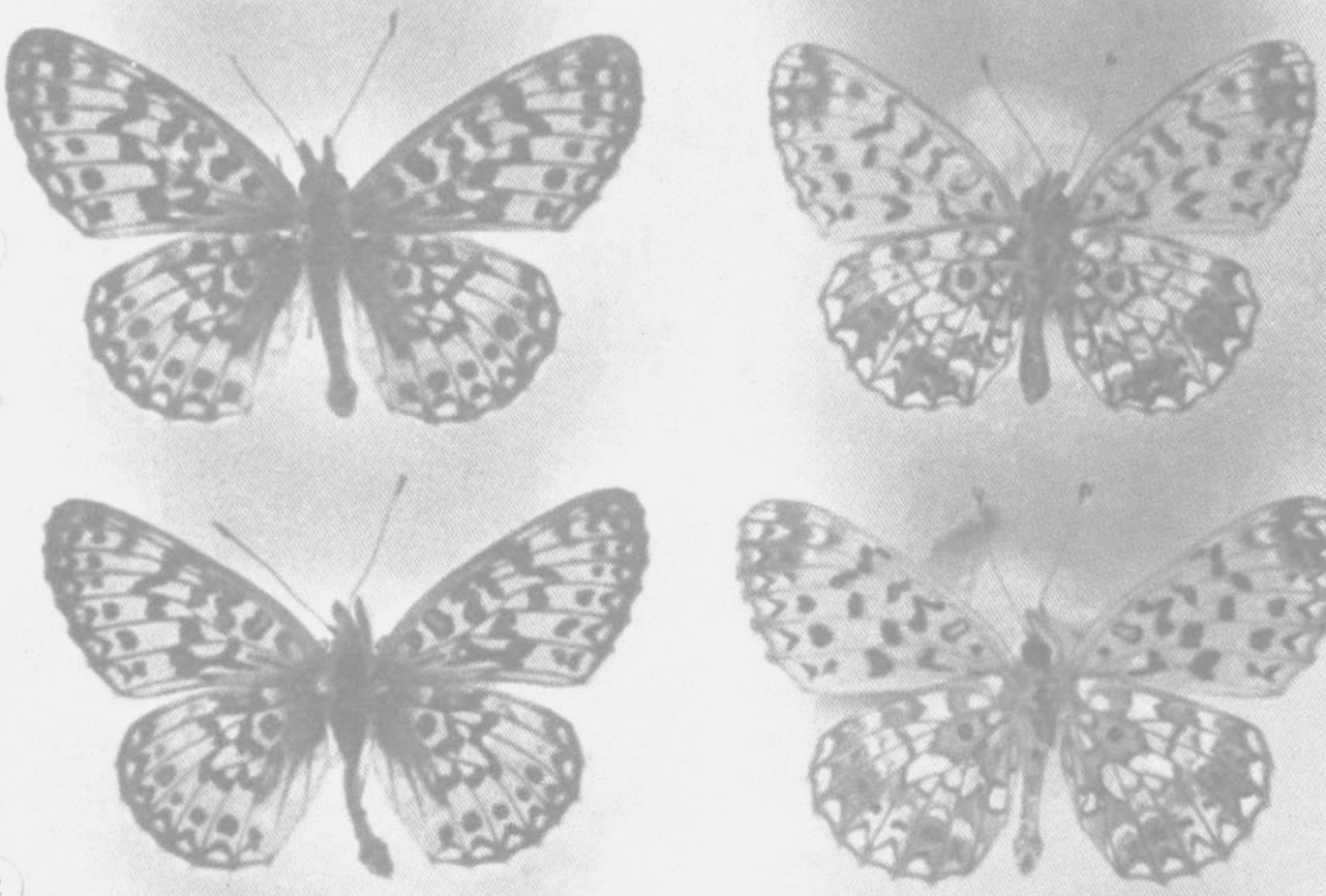

C
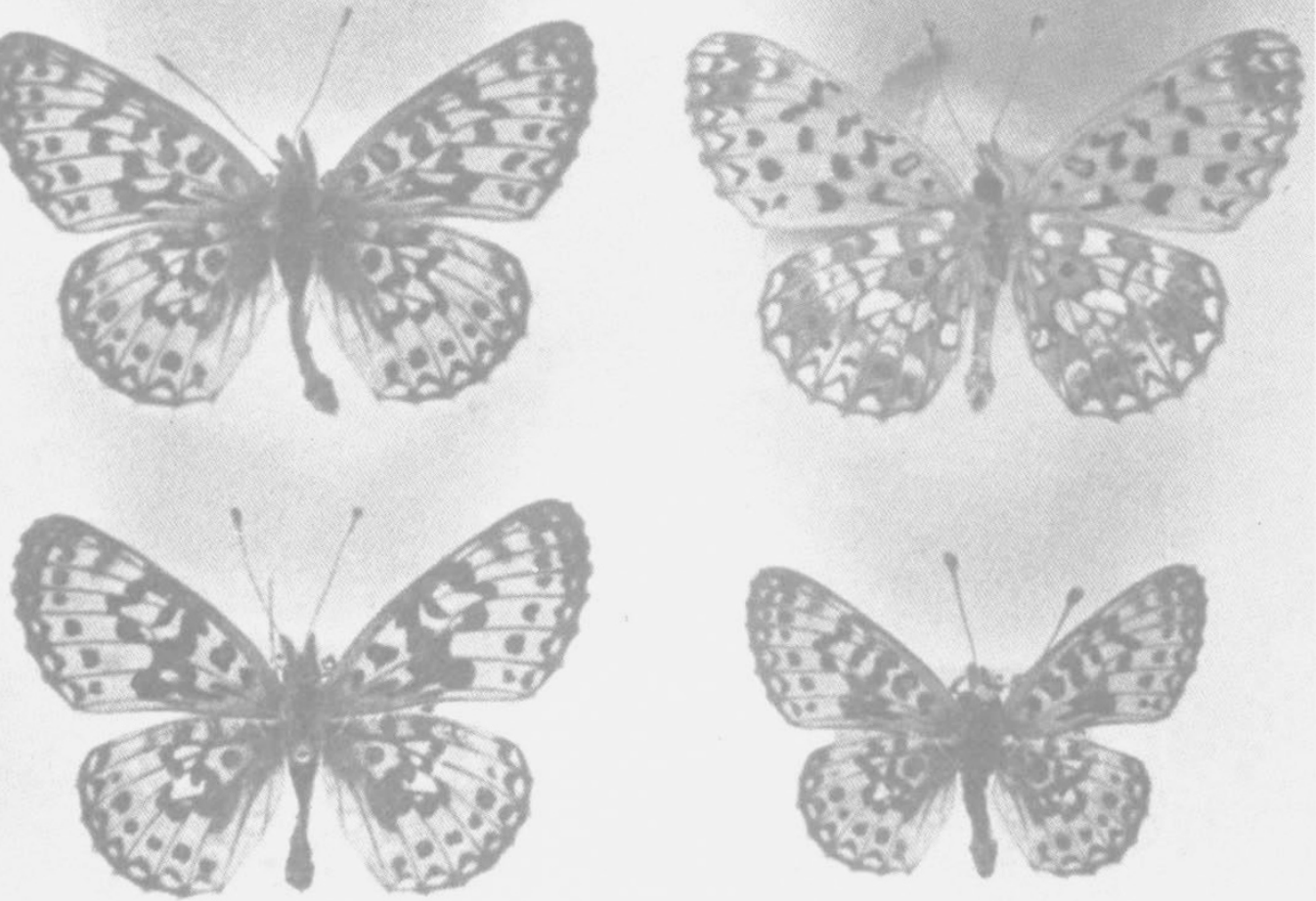

Explanation of PLATE-Adult male Boloria selene (dorsal and ventral views). (A) From Acton, Middlesex Co., Mass., U.S.A.; (B) from Pamber Forest, Berkshire, England; and $(C)$ Massachusetts $\times$ England $F_{1}$ interpopulation hybrids. 
seen during several visits in July, August, and September. Several normally univoltine species of Lepidoptera (Arctia caja L. (Julian Donohue, pers. comm.), Phyciodes batesii Reakirt (Oliver, in prep.), and certain populations of Phyciodes tharos Drury (Oliver, unpubl. data)) become wholly or partially multivoltine in the laboratory when cultured under similar photoperiod conditions giving longer days and shorter nights than those encountered in nature.

No significant differences were found between larvae or pupae of the two populations. Adults are generally similar in appearance (see plate). However, the following distinctions can be made in wing colour pattern:

Massachusetts English

Dorsal

1. Wing bases less heavily dark pigmented.

2. Forewing dark markings broader, less crisp.

1. Wing bases heavily dark pigmented.

2. Dark markings narrower, more crisply defined.

\section{Ventral}

1. Brown colour lighter.

2. Hindwing basal black spot very small.

3. Next to last hindwing medial light spot silvered.

1. Brown colour darker.

2. Hindwing basal black approximately three times larger.

3. Spot usually cream colour.

\section{Results}

\section{(i) Hybrid phenotypes}

The hybrid adults showed the full range of phenotypic variation between the parental types. The hybrids were no larger in size than their parents; some were very much dwarfed (see plate). About one-half of the hybrids had dorsal black wing markings darker than those of their parents, and in $10 / 47$ the basal and medial markings coalesced into black patches.

\section{(ii) Egg fertility and embryonic viability}

There were marked reductions in hybrid egg fertility $(P=0.02)$ and embryonic viability $(\mathrm{P}<0.002)$ (table 1$)$. Variation in both values was much higher for the hybrids than for the parental broods. The one backcross mating made produced very few fertile eggs, none of which hatched. There were an additional three hybrid and two backcross matings which produced no fertile eggs and are not included in table 1.

\section{(iii) Mortality}

Hybrid larval mortality during the first instar was high, but not as great as that of the English parental culture (table 2). Hybrid mortality in later stages was low, and the total mortality throughout development was lower than for either parental culture. 


\section{(iv) Voltinism}

Considering all hybrid broods together, a greater proportion of larvae which survived to the second instar diapaused than in the English parental stock (table 2), though the difference is not statistically significant.

\section{TABLE 1}

Egg fertility (fertile/laid) and embryonic viability (hatched/fertile) of Boloria selenc broods from wildcollected females and laboratory control, $F_{1}$ hybrid, and backcross matings. Significance tests refer to comparison of hybrid series with parental values (wild-collected females and control matings)

Origin and brood no. No. of eggs Fertile/laid Hatched/fertile Wild-collected females and control matings

Acton, Massachusetts

$\begin{array}{lrrr}68-2 & 68 & 0 \cdot 985 & 0 \cdot 955 \\ 68-3 & 102 & 0 \cdot 961 & 0 \cdot 938 \\ 70-1 & 281 & 1 \cdot 000 & 0 \cdot 940 \\ 70-2 & 201 & 0.965 & 0 \cdot 948 \\ 70-4 & 222 & 0 \cdot 973 & 0 \cdot 963 \\ 70-8 & 133 & 0 \cdot 888 & 0 \cdot 992 \\ 70-10 & 153 & 0 \cdot 948 & 0 \cdot 814 \\ 71-4 & 84 & 1.000 & 0 \cdot 965 \\ 71-15 & 60 & 1.000 & 0 \cdot 983\end{array}$

Berkshire, England

$\begin{array}{crcc}71-1 & 107 & 1.000 & 0.990 \\ 71-2 & 151 & 0.994 & 0.993 \\ 71-3 & 80 & 0.988 & 0.962 \\ 71-9 & 225 & 0.991 & 1.000 \\ & \bar{X} \text { (with S.D.) } 0.975 \pm 0.154 & 0.958 \pm 0.080\end{array}$

Mass. $q \times$ English 0

$\mathrm{F}_{1}$ hybrids

$\begin{array}{lrrl}71-5 & 312 & 0.951 & 0.960 \\ 71-6 & 180 & 0.817 & 0.695 \\ 71-7 & 113 & 0.893 & 0.782 \\ 71-8 & 263 & 0.917 & 0.705 \\ 71-12 & 42 & 0.548 & 0.348 \\ 71-13 & 107 & 0.925 & 0.646\end{array}$

English $q \times$ Mass. $d$

$71-14$

$$
\begin{array}{ccc}
93 & 1.000 & 0.925 \\
\text { X (with S.D.) } & \begin{array}{c}
0.864 \pm 0.254 \\
(\mathrm{P}=0.02)
\end{array} & 0.723 \pm 0.224 \\
& (\mathrm{P}<0.002)
\end{array}
$$

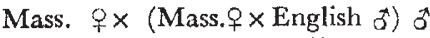
71-17

Backcross

$$
61 \quad 0 \cdot 115 \quad 0.000
$$

(v) Sex ratio

There were significantly $(\mathrm{P}<0.025)$ more male adults in the combined hybrid broods than in broods of the combined parental stocks (hybrids-41

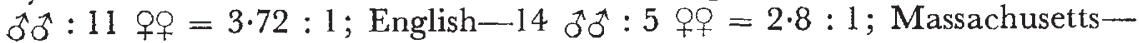




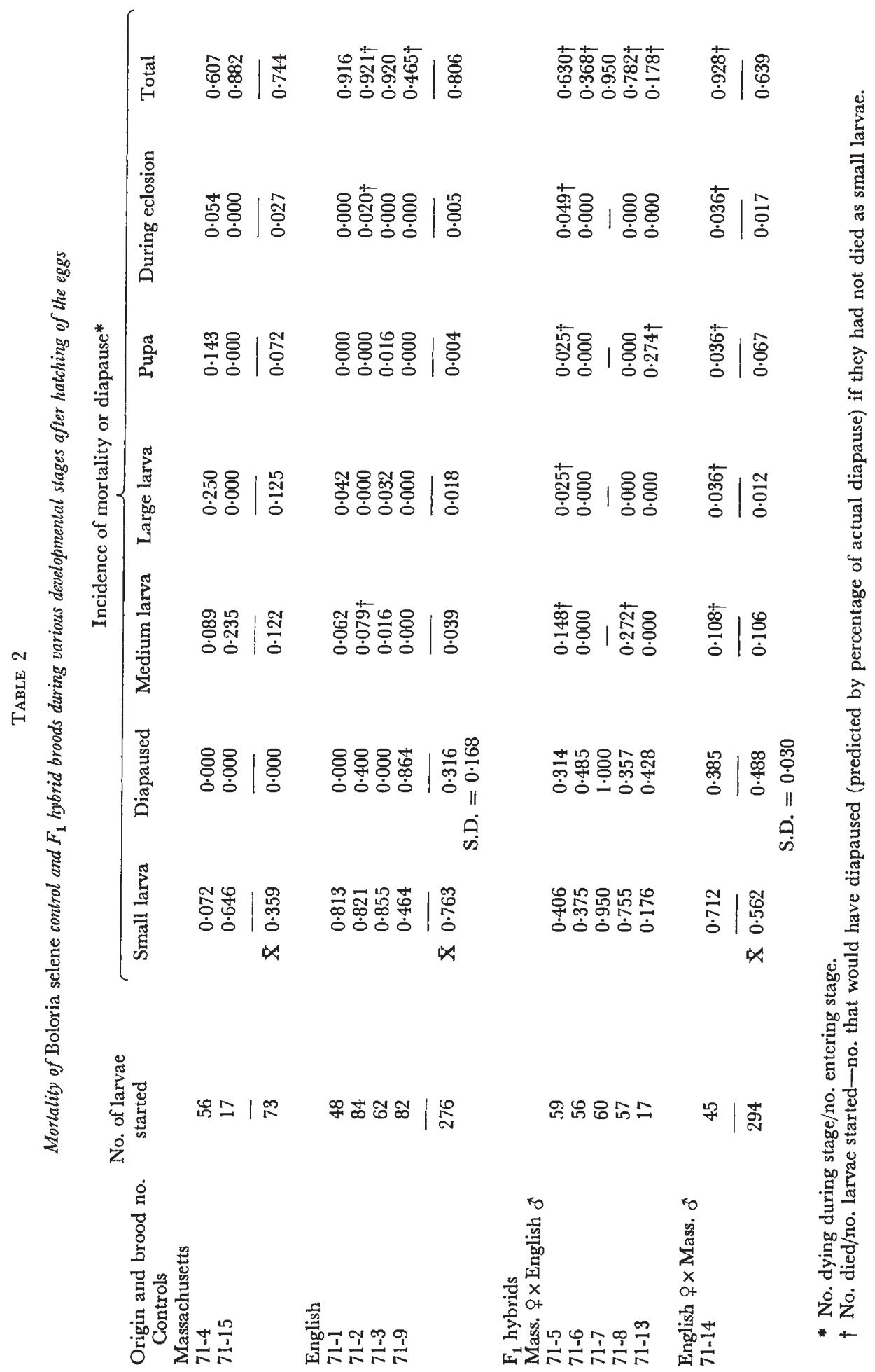


16 ㅊㅎ : 11 우우 $=1.45: 1$; combined parental broods-30 추 $: 16$ 우우 = $1 \cdot 88: 1)$. The small numbers of successfully reared adults do not permit a more detailed analysis of the sex ratio data.

\section{Discussion}

The results indicate that extensive genetic incompatibility has evolved between the two populations. The lowered embryonic viability, deficiency of female adults, and frequent dwarfing of adults in the hybrid broods is a result of the action of this incompatibility during development and reflects differing physiological adaptations.

Apparently development of the black pattern elements of the adult forewing is controlled by differing genetic means in the two populations. Those individuals whose dark forewing markings have coalesced probably have received a "double dose " of genetic material influencing the expression of the markings. This is an indication that there has been selection for stabilisation of phenotype, even though the populations may differ in the exact genetic means used to achieve similar phenotypes. Thus, individuals of the two populations may look more alike than they actually are.

The high variation in embryonic viability among the hybrid broods indicates that incompatibility here is due to relatively few discretely-acting genes or groups of genes. A significant degree of differentiation between populations should involve a relatively large number of genes or gene groups upon which selection has acted. Since there has been no selection for incompatibility per se, serious incompatibility occurring in several different aspects of the life cycle (e.g. embryonic viability, sex ratio, adult vigour) should be a fairly reliable indicator of a relatively high degree of genetic differentiation. Minor incompatibility in several aspects should indicate relatively slight differentiation, whereas serious incompatibility occurring in only one aspect would indicate slight differentiation which happens directly to affect one aspect of viability.

Reduction in hybrid fertility, that is, the fertility of cggs from hybridparental backcross matings, is due to a disruption of the normal process of meiosis. This may result from either difficulties in chromosome pairing during meiosis or parental differcnces in genetic control of the meiotic process. Fertility was very low in the one backcross mating obtained.

These results differ mainly in degree from previous findings on interpopulation hybrids within the United States (Oliver, 1972a). The fertility of $B$. selene hybrids made between populations from the Black Hills, South Dakota, and the same Massachusetts population was much higher (68.8 per cent egg fertility in two backcross matings as opposed to 11.5 per cent in one mating). The small number of observations makes a comparison risky, but incompatibility in the South Dakota $\times$ Massachusetts cross was much less in hybrid embryonic viability ( 88.8 per cent of eggs fertile, 89.0 per cent of fertile eggs hatched), sex ratio (normal), and hybrid larval, pupal, and adult development (no dwarfs, normal mortality).

Interpopulation hybrids of other United States lepidopteran species (Boloria toddi (Holland), Phyciodes tharos Drury (both Nymphalidac), and Cisseps fulvicollis (Hübner) (Ctenuchidae) (Oliver, 1972a) or of the European satyrid Pararge megera L. (Oliver, 1972b) show the same sort of evidence of incompatibility. However, all of these populations are less geographically 
isolated and show a generally lower level of incompatibility than do the English and Massachusetts populations of $B$. selene. This latter incompatibility may be as great as would be expected from a cross between separate, closely-related species.

Hybrid broods between closely-related species of the Papilio machaon L. group (Papilionidae), for example, usually show good embryonic viability but extreme abnormalities of sex ratio with deficiencies of either sex occurring (Clarke and Sheppard, 1955, 1956; Remington, 1968; author's unpubl. data). The same sort of sex ratio abnormalities occur in hybrids within the nymphalid butterfly genera Limenitis (Remington, 1956; Platt and Greenfield, 1971) and Phyciodes (Oliver, unpubl. data). In Phyciodes crosses between well-differentiated, sympatric species show reductions in $\mathrm{F}_{1}$ hybrid embryonic viability comparable to those shown in the present crosses involving $B$. selene. Crosses between the closely-related Pieris napi L. and P. bryoniae Hübner (Pieridae) show good egg fertility and embryonic viability and only slight sex ratio abnormalities, but serious incompatibility is revealed by a breakdown of synchrony of hybrid adult emergence of the two sexes and by the occurrence of hybrid sexual mosaics (Bowden, 1953, 1956).

Acknowledgments.-This research was supported in part by a Grant-in-Aid of Research from the Society of the Sigma Xi. I am grateful to the Hope Department of Entomology, University of Oxford, England, for the use of laboratory facilities during my visit there in 1970 and 1971. I would like to thank Mr B. R. Baker of the Reading Museum, Reading, England, for his help in locating the English population of Boloria selene mentioned in this paper.

\section{REFERENGES}

BOWDEN, s. R. 1953. Timing of imaginal development in male and female hybrid Pieridae (Lep.). The Entomologist, 86, 255-264.

BowDen, S. R. 1956. Hybrids within the European Pieris napi L. species group. Proc. S. Lond. Entomol. Nat. Hist. Soc., 1954-55, 135-159.

CLARKe, c. A. 1952. Hand pairing of Papilio machaon in February. Entomol. Rec., 64, 98-100.

CLARKE, C. A., AND SHEPPARD, P. M. 1955. A preliminary report on the genetics of the machaon group of swallowtail butterflies. Evolution, 9, 182-201.

GLARKE, G. A., AND SHEPPARD, P. M. 1956. A further report on the genetics of the machaon group of swallowtail butterflies. Evolution, 10, 66-73.

KIMURA, M., AND WEIss, G. H. 1964. The stepping stone model of population structure and the decrease of genetic correlation with distance. Genetics, 49, 561-576.

oliver, G. G. 1972a. Genetic and phenotypic differentiation and geographic distance in four species of Lepidoptera. Evolution, 26, 221-241.

oliver, a. G. 1972b. Genetic differentiation between English and French populations of the satyrid butterfly Pararge megera. Heredity, 29, 307-313.

PlatT, A. P., AND GREENFIELD, J. C., JR. 1971. Interspecific hybridization between Limenitis arthemis and L. archippus (Nymphalidae). F. Lepid. Soc., 25, 278-284.

Remington, C. L. 1956. Genetics of populations of Lepidoptera. Proc. 10th Intern. Congr. Entomol., 2, 787-806.

Remington, G. L. 1968. A new sibling Papilio from the Rocky Mountains, with genetic and biological notes (Insecta, Lepidoptera). Postilla, 119, 1-40. 